\title{
Study of Urban Heat Island Trends to Aid in Urban Planning in Nakuru County-Kenya
}

\author{
Charity W. Kimuku, Moses Ngigi \\ Institute of Geomatics, GIS and Remote Sensing, Dedan Kimathi University of Technology, Nyeri, Kenya \\ Email: charitykimuku@gmail.com
}

How to cite this paper: Kimuku, C.W. and Ngigi, M. (2017) Study of Urban Heat Island Trends to Aid in Urban Planning in Nakuru County-Kenya. Journal of Geographic Information System, 9, 309-325. https://doi.org/10.4236/jgis.2017.93019

Received: March 8, 2017

Accepted: June 12, 2017

Published: June 15, 2017

Copyright $\odot 2017$ by authors and Scientific Research Publishing Inc. This work is licensed under the Creative Commons Attribution International License (CC BY 4.0).

http://creativecommons.org/licenses/by/4.0/ (c) (i) Open Access

\begin{abstract}
Urban Heat Island (UHI) is a phenomenon characterized by higher surface and atmospheric temperatures in urbanized areas as compared to the surrounding rural areas. This phenomenon is a consequence of increase in Land Surface Temperatures (LST) as a result of trapped heat energy on the surface. The objective of this study is establishing the trends in and relationship between LST and land use/land cover in Nakuru County as it seeks to achieve the ultimate goal to contain the UHI effect. Urban heat island inference was based on the generation of a time series set of Landsat imagery, with particular emphasis on the thermal band. Land use/land cover mapping was conducted using maximum likelihood classification techniques, and this, like the LST, is generated in a time series fashion from 1989 to 2015. Accuracy assessment was conducted in order to give confidence in the classification results. The accuracy of the development was assessed using observed temperature data as recorded by the ground stations at the Kenya Meteorological Department. This study employed Normalized NDVI and NDBI to investigate the variation land use/land cover. Results revealed that over the years, settlement has been on an upward trend in terms of area whereas forests have been decreasing due to deforestation. Also, the land surface temperatures have been increasing over the years. In order to qualify this, the correlation between LST and Land Use change was conducted and it indicated that changes to settlement/urban increased proportionately with Land Surface Temperature.
\end{abstract}

\section{Keywords}

Urban Heat Island, Land Surface Temperature, NDVI, NDBI, Land Use

\section{Introduction}

Urban Heat Island (UHI) is a phenomenon characterized by higher atmospheric and surface temperatures in urbanized areas than in surrounding rural areas. It 
is an environmental consequence of physical change of the surface of urban areas from natural landscape into impervious surfaces as a result of urbanization and industrialization [1]. Typically, urbanization leads to reduction of natural landscape [2], which results into modification of surface water content and vegetation cover. When green spaces in the urban centers are replaced by impervious surfaces of construction materials, the thermal, radioactive, moisture and aerodynamic properties of that surface and temperature are altered.

This is because urban construction materials have different heat capacity and thermal conductivity and radioactive (reflectivity and emissivity) properties compared to surrounding rural areas, which results in more of the heat energy being absorbed and stored in urban surfaces compared to rural surfaces. This phenomenon was first investigated and identified by Luke Howard in 1818 . Thereafter, medical doctors studied the UHI phenomenon to deduce the connection between the air quality, air temperatures and health in urban areas. Later, scientists were able to establish the environmental factors contributing into the UHI phenomenon.

Cement walls, dark roofs and paved surfaces in urban areas absorb more sunlight, trap heat and increase local temperatures. Urban areas have more manmade surfaces than green or natural surfaces. The concentration of this heat absorbing surfaces creates islands where temperatures are higher. According to [3], observations have shown that the temperatures of urban centers can be up to $12^{\circ} \mathrm{C}$ higher than neighboring regions. Once the heat is trapped by these artificial surfaces, the Land Surface Temperature (LST) propagated both downward into the subsurface layers [4] and upward into the atmosphere resulting into heating up of the subsurface, the surface and atmosphere-the urban heat island.

Urban development has serious effects on the global environmental quality, including the quality of air, increase in temperature and traffic congestion. Higher urban temperatures generally result in adverse economic and environmental impacts locally, regionally and globally. Persistent higher temperatures increase the demand for air conditioning, raise pollution levels, change urban thermal environments and ultimately lead to thermal discomforts and incidence of heat-related illnesses. It is essentially a form of thermal pollution caused by human activities and force driving local climate changes [5].

Studies have been directed to analyze and establish the relationship between the LST and percent ISA in urban, NDVI and the related UHI effect in urban expansions. Satellite imagery has been used to establish comparative studies between NDVI and percent ISA by investigating LST, percent ISA and NDVI [5]. LST is an effective predictor of energy-water exchanges between the land surface and atmosphere which is a direct link to human-environment interaction. LST data is derived from Thermal Infra-Red (TIR) band of radiometrically and geometrically corrected satellite images [6].

According to [7], the UHI effect is caused by a number of factors which interact with each another. One of them is heat release resulting from energy consumption in urban areas know as anthropogenic heat release. Secondly are the 
changes in land cover from natural land cover to manmade features such as buildings and pavements which reduces surface evapotranspiration capacity due to less green areas. In addition heat is stored in construction materials such as concrete and asphalt. The third cause is the form of the urban center.

High rise buildings increase the surface area for absorption of heat and stagnate the heat since they are densely packed. Finally the urban activities such as movement of motor vehicles cause the greenhouse effects of fine-particulate air pollution in the urban atmosphere. The urban heat Island causes long term rise in average temperatures as well as sweltering nights and rising daytime temperatures.

According to [8], in his study, carried out a research on the dynamism of land use changes on surface temperatures in Kenya. The study was carried out in Nairobi which is the capital city, the main aim of the study was to examine effects of land use change on surface temperature. This mission was accomplished by analysing the relationship between LST, NDVI and LULC for a duration of 24 years. Satellite images for years 1986, 1995, 2002 and 2010 were used to derive NDVI, LULC and LST. To retrieve the land use/land cover Landsat data was used to carry out classification from which a total of five classes were obtained namely built-up, agricultural, grassland, water and bare land. Thereafter, accuracy assessment was done by randomly selecting points in which high resolution images were checked against the classified images.

Normalized difference vegetation index was retrieved from near infrared and red bands and LST was retrieved by first converting the digital number to spectral radiance. The result of this study demonstrated that there existed negative correlation between NDVI and LST which was an indication of reduction in vegetation cover to bare land and built-up which would lead to increase in LST.

\section{Materials and Methods}

\subsection{Study Area}

The town is located $160 \mathrm{~km}$ North West of Nairobi and is the fourth largest urban Centre in Kenya after Nairobi, Mombasa and Kisumu. It covers $1.29 \%$ of the total land mass in Kenya, over an area of $7495.07 \mathrm{~km}^{2}$ in the central parts of Kenya's rift valley highlands located between longitudes $35^{\circ} 28^{\prime \prime}$ and $35^{\circ} 36^{\prime \prime}$ and latitudes $0^{\circ} 12^{\prime \prime}$ and $1^{\circ} 10^{\prime \prime}$ South. Shaped like a stone-age axe, it is bordered by the County of Baringo to the north, County of Kericho to the north-west, County of Bomet to the west, County of Narok and County of Kajiado to the south, County of Kiambu to the south east, County of Nyandarua to the east, and County of Laikipia to the north-east (Figure 1).

\subsection{Required Datasets}

Various datasets were collected from different sources for Urban Heat Island trends analysis. The temperature data obtained from Kenya Meteorological Department for the year 1989, 2000, 2010 and 2016, Lands at Imagery were obtained from Regional Centre for Mapping of Resources for Development. The 


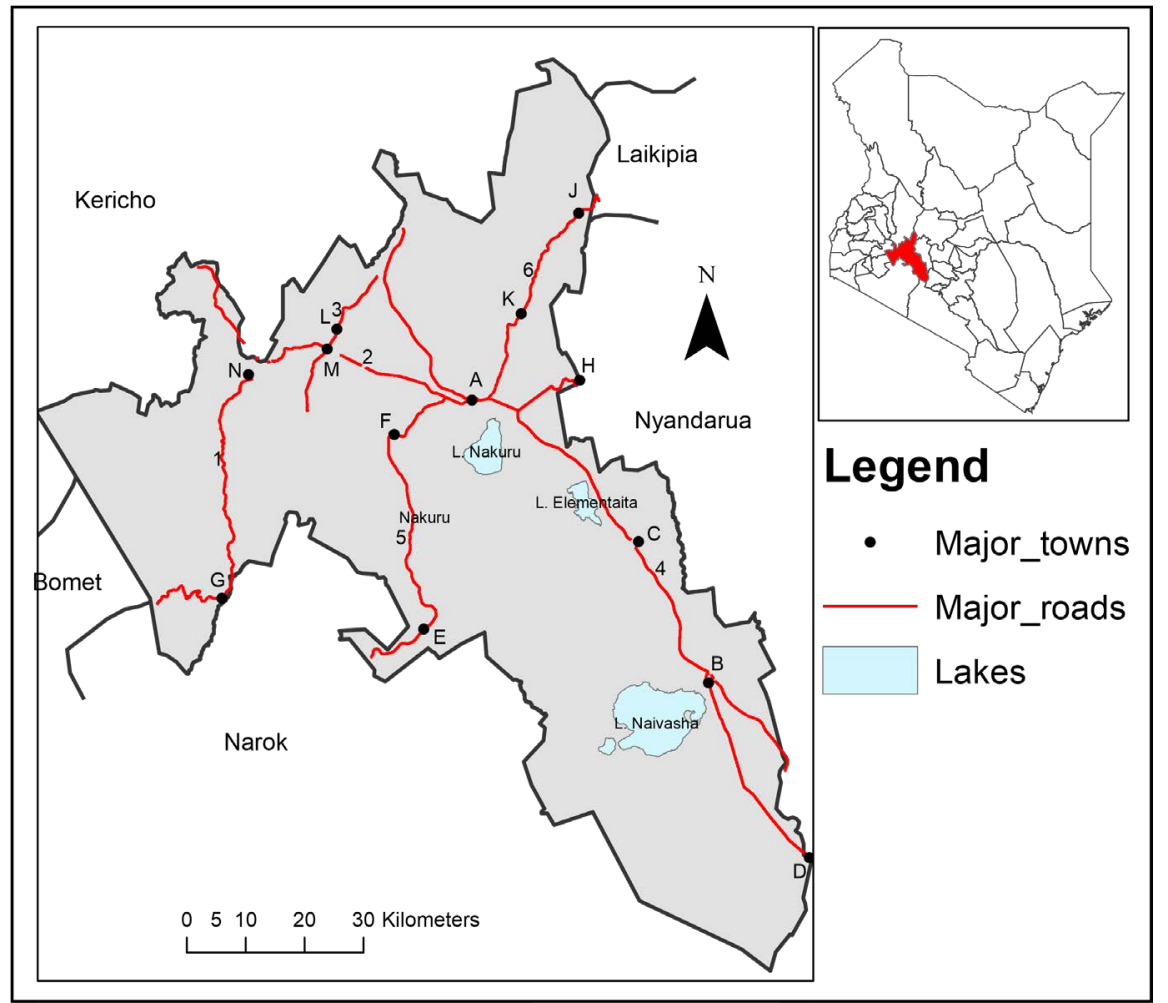

Figure 1. Study area diagram.

base map data for retrieval of administration boundaries was obtained from survey of Kenya. Table 1 shows the required datasets and their sources.

\subsection{Research Approach}

The research approach was summarized as follows. First, satellite imagery was downloaded and per-processed, specifically image enhanced to facilitate both visual and digital image analysis. The image was processed in two steps. First, the thermal band was extracted and processed to derive the land surface temperature, through a series of intermediate procedures.

The thermal Infrared DN data was converted to Top of the Atmosphere spectral radiance using the radiance rescaling factors provided in the metadata file. The radiance values of all pixels were thereafter converted to the effective at-satellite temperature of the viewed Earth-atmosphere system, under the assumption of a uniform emissivity before finally being transformed to Land Surface Temperature.

In the second step, the imagery was layer stacked into a composite and subjected to information extraction through maximum likelihood classification in order to derive the land use/land cover classes for the respective years after which accuracy assessment was conducted for error reporting. Change detection was conducted to derive the change matrix and the areas for the respective land use classes for the various epochs (1989-2000, 2000-2010 and 2010-2016).

The extracted land surface temperature was correlated with the derived change statistics to determine if and how they compare. Consequently, regre- 
Table 1. Data sources and their characteristics.

\begin{tabular}{cccc}
\hline Data & Source & Characteristics & Purpose \\
\hline Landsat Imagery & RCMRD & $\begin{array}{c}\text { Resolution } 15 \mathrm{~m} \\
\text { (pan-sharpened) }\end{array}$ & $\begin{array}{c}\text { Land use/land cover } \\
\text { classification and processing of } \\
\text { land surface temperature }\end{array}$ \\
$\begin{array}{c}\text { Administrative } \\
\text { Boundaries }\end{array}$ & $\begin{array}{c}\text { Survey of } \\
\text { Kenya }\end{array}$ & Shapefile & $\begin{array}{c}\text { Mapping of } \\
\text { administrative units }\end{array}$ \\
$\begin{array}{c}\text { Policy Documents } \\
\text { Kemperature Data }\end{array}$ & KNBS & Documented Reports & Spreadsheet \\
\hline
\end{tabular}

sion modelling was adopted to simulate future LST predictions for the year 2025, estimating a decade from the year 2016. This was used to maintain approximately a 10 year interval of the epochs. The datasets, which include climatic data, satellite imagery and administrative boundary were first sourced from the Kenya Meteorological Department, Glovis website and Survey of Kenya respectively.

The thermal band of the satellite imagery was used to derive the land surface temperature by first converting the $\mathrm{DN}$ values to radiance. The radiance values were then converted to top of the atmosphere brightness from which surface emissivity was derived. The visible and near-infrared bands were used in image classification to generate information classes after which post classification change detection was conducted to derive change statistics and change matrices, which shows what classes changed from what to what and by what area.

The climate data, obtained from KMD was used in validating the land surface temperature for the purposes of error reporting and accuracy assessment. With the results of the validation being satisfactory, the land surface temperature was then correlated with the change statistics. In simulating the LST for 2025, regions of influence were obtained using Thiessen polygons, about the ground stations, and LST was derived for each polygon.

\subsection{Correlation of Land Cover Changes vs. Land Surface Temperature}

The correlation between land use/land cover and land surface temperature changes was done to compare how the two variables change with respect to one another. The land use variable was estimated from the area as computed from land use/land cover maps whereas the temperature variable was estimated from the satellite derived metrics. The underlying assumption in this case was that the urban areas were represented by the settlement class and as such, the changes in land surface temperature was plotted against the changes in settlement acreages. Since the acreages (ha) and temperature (degree Celsius) had different units, the $y$-axis was represented by two scales.

\subsection{Simulating Land Surface Temperature for 2025}

A three step method was applied in order to simulate LST for 2025. First, a cor- 
relation (bivariate) analysis was conducted between each land cover index (NDVI and NDBI) and the LST for each of the time periods (1989, 2000, 2010, and 2016) in order to explore the relationships over the periods.

Second, if the bivariate correlations are significant, a multiple regression analysis using the derived LST for 2016 as the dependent variable and the two land cover indices (NDVI and NDBI) for 2016 as independent variable was warranted in order derive a regression equation to be used for projecting the future indices (2025). The equations for calculating the NDVI and NDBI are as follows:

$$
\mathrm{NDVI}=\frac{\mathrm{NIR}+\mathrm{R}}{\mathrm{NIR}+\mathrm{R}}
$$

where: NIR is the near infrared band $4, \mathrm{R}$ is the red band 3 .

$$
\mathrm{NDBI}=\frac{\mathrm{VNIR}+\mathrm{SWIR}}{\mathrm{VNIR}+\mathrm{SWIR}}
$$

where: VNIR is Visible Near Infrared, SWIR is Short wave Infrared.

Third, the two indices (NDVI and NDBI) were simulated for the year 2025 using the multivariate linear regression, in which the Land Surface Temperature was the dependent variable whereas the NDVI and NDBI were the dependent variables. The coefficients of the multi variate linear regression were obtained using historical data for LST, NDVI and NDBI as obtained from satellite image analysis.

This generation of the coefficients is performed through a least squares adjustment and these facilitated the generation of an interpolating polynomial in the form of a multi-variate regression equation. It is this polynomial that shall form the basis of predicting the mean LST value for 2025. It follows, therefore, that in order to predict LST for 2025 using the polynomial, we have to predict NDVI and NDBI for 2025 as they act as independent variables in the polynomial.

This procedure was achieved by analyzing the growth trends in NDVI and NDBI for the historical years under consideration, after which a prediction of the two variables were made, assuming the trends continue in the same fashion. This resulted in predicted values of NDBI and NDBI for 2025 which were then input into the prediction model to generate predicted meant LST for 2025.

Regions of influence were generated by forming Thiessen polygons about the ground stations obtained from the Kenya Meteorological Department. Thiessen polygons is a method for constructing surface models from a discrete set of arbitrarily described data. The surface is represented as a network of planar, triangular faces with vertices at the data points, which is built up on a Delaunay triangulation of the data point projections on the $x-y$ plane. Within each of these polygons, NDVI and NDBI was predicted for 2025, assuming linear regression, and these were used as input to the interpolating polynomial to derive LST for each region of influence, resulting in a final surface, showing variations in LST across Nakuru county. 


\section{Results and Discussions}

\subsection{Modeling Land Use Change}

The images for the years of study i.e. 1989, 2000, 2010 and 2016 were classified into five broad classes namely; Settlement, Wetland, Forestland, Grassland, and Cropland. The general Trend was a negative change for land use lands cover type Cropland, Forestland, Grassland and Wetland while settlement had a positive change to indicate that there has been increase in the number of settlements over the years. There is however an increase in coverage of the Cropland in the last epoch. Figure 2 shows the trends in land use/land cover over the epochs.

The variations of the land use/land cover type between the epochs were not of equal proportions. Grassland had the greatest variations, initially showing a slight increase, a drop in the middle and a sharp increase in the last epoch so that the general change is an increase in grassland coverage. This variation is associated to the time of the year when the satellite data was obtained. Cropland, Forestland and Wetland decreased drastically over the three epochs resulting into a reduced coverage. Settlement displayed a uniform trend, with a positive percentage change over the three epochs. The percentage variation over each epoch is based on the amount of change as compared to the base year 1989. Figure 3 shows the percentage variation for all land use/land cover over the years of study.

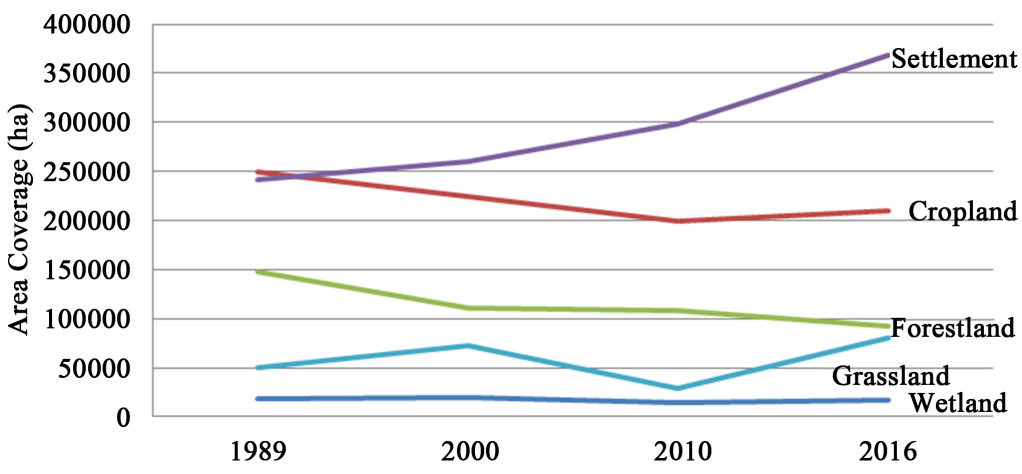

Figure 2. Trends in land use/land cover.

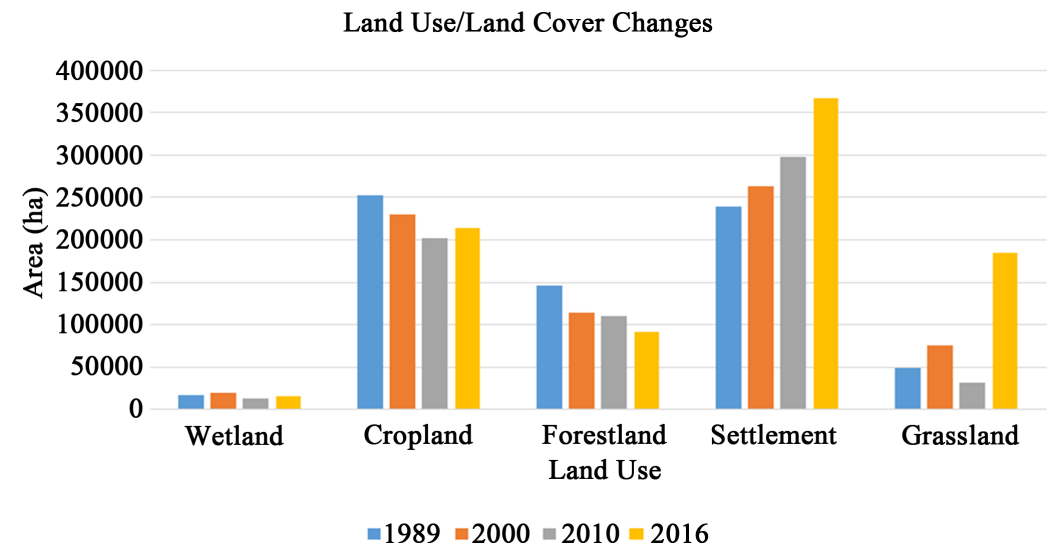

Figure 3. Percentage variation in land use/land cover changes. 
In analyzing the changes in the three epochs under consideration, the change matrix was generated based on the historical imageries that had been classified earlier. The change matrix indicated by what area a particular class changed to the other. The classes in the column indicate the "from" classes whereas those in the row indicated the "to" classes. Tables 2-4 shows the cross tabulation of land use/land cover for the epochs under consideration.

The overall trends of change from other land use to settlement in percentage for the land use areas shows no regular pattern. However, changes in areas of grassland depict a significant regular pattern. For instance, the area of grassland within the epoch 1989-2000 was about 10\% whereas in the epoch 2000-2010 it increased to $27 \%$ and in the epoch 2010-2016, there was an increased to about $37 \%$. The trends of changes in percentage shows that in all the land uses, there is an increase to settlement. This implies that settlement have been increasing over the years which is attributed to urbanization (Table 5).

Table 2. Cross tabulation of land use/land cover changes 1989-2000.

\begin{tabular}{rccccccc}
\hline & \multicolumn{7}{c}{2000} \\
\cline { 3 - 8 } & & Forestland & Grassland & Cropland & Wetland & Settlement & Totals \\
\hline \multirow{2}{*}{1989} & Forestland & $43,301.70$ & $44,914.10$ & $23,843.90$ & 353.25 & 87.12 & $112,500.07$ \\
& Grassland & $13,860.20$ & $297,833.00$ & $133,733.00$ & 897.93 & $2,463.93$ & $448,788.06$ \\
& Cropland & $2,038.32$ & $60,550.60$ & $96,660.20$ & 152.91 & 395.73 & $159,797.76$ \\
& Wetland & 495.63 & $1,242.72$ & 443.70 & $18,209.30$ & 147.15 & $20,538.50$ \\
& Settlement & 119.34 & $3,568.59$ & 646.38 & 359.55 & 494.64 & $5,188.50$ \\
& Totals & $59,815.19$ & $408,109.01$ & $255,327.18$ & $19,972.94$ & $3,588.57$ & \\
\hline
\end{tabular}

Table 3. Cross tabulation of land use/land cover changes 2000-2010.

\begin{tabular}{rccccccc}
\hline & \multicolumn{7}{c}{2010} \\
\cline { 3 - 8 } & & Forestland & Grassland & Cropland & Wetland & Settlement & Total \\
\hline \multirow{2}{*}{2000} & Forestland & $27,541.10$ & $19,669.60$ & $12,217.80$ & 258.84 & 127.89 & $59,815.23$ \\
& Grassland & $20,138.30$ & $267,479.00$ & $116,451.00$ & 762.93 & 3277.44 & $408,108.67$ \\
& Cropland & 6525.81 & $85,707.10$ & $161,834.00$ & 193.14 & 1067.13 & $255,327.18$ \\
& Wetland & 297.45 & 2288.70 & 480.06 & $16,502.30$ & 404.37 & $19,972.88$ \\
& Settlement & 47.97 & 1818.45 & 658.17 & 85.41 & 978.57 & 3588.57 \\
\hline
\end{tabular}

Table 4. Cross tabulation of land use/land cover changes 2010-2014.

\begin{tabular}{rccccccc}
\hline & \multicolumn{7}{c}{2016} \\
\cline { 3 - 8 } & & \multicolumn{7}{c}{ Forestland } & Grassland & Cropland & Wetland & Settlement & Total \\
\hline \multirow{2}{*}{2010} & Forestland & $38,004.70$ & $10,416.20$ & 5806.53 & 282.60 & 40.68 & $54,550.71$ \\
& Grassland & $22,254.90$ & $50,172.00$ & $96,888.70$ & 5704.65 & 1942.65 & $376,962.90$ \\
& Cropland & $11,149.50$ & $91,972.30$ & $86,092.00$ & 1469.16 & 958.32 & $291,641.28$ \\
& Wetland & 49.32 & 284.31 & 114.21 & 7330.40 & 24.39 & $17,802.63$ \\
& Settlement & 23.94 & 2049.48 & 871.92 & 746.91 & 2163.15 & 5855.40 \\
\hline
\end{tabular}


Table 5. Percentage changes from other land use/land covers to settlement.

\begin{tabular}{ccccccc}
\hline \multirow{2}{*}{ Land Use } & \multicolumn{2}{c}{$1989-2000$} & \multicolumn{2}{c}{$2000-2010$} & \multicolumn{2}{c}{$2010-2016$} \\
\cline { 2 - 7 } & Hectares & Percentage & Hectares & Percentage & Hectares & Percentage \\
\hline Wetland & 87.12 & $0.08 \%$ & 127.89 & $0.21 \%$ & 40.68 & $0.07 \%$ \\
Cropland & $2,463.93$ & $0.55 \%$ & $3,277.44$ & $0.80 \%$ & $1,942.65$ & $0.52 \%$ \\
Forestland & 395.73 & $0.25 \%$ & $1,067.13$ & $0.42 \%$ & 958.32 & $0.33 \%$ \\
Settlement & 147.15 & $0.72 \%$ & 404.37 & $2.02 \%$ & 24.39 & $0.14 \%$ \\
Grassland & 494.64 & $9.53 \%$ & 978.57 & $27.27 \%$ & $2,163.15$ & $36.94 \%$ \\
\hline
\end{tabular}

\subsection{Analysis of Land Surface Temperature}

From the derived land surface temperature, it was observed that as the years progressed, the surface temperatures continually increased, a factor attributed to the rise in urbanization. The variation in land surface temperature for the year 1989 was such that the areas with extremely high temperature were not as much as they are in the year 2000. Similarly, the areas with extremely high temperatures increased in the subsequent years 2010 and 2016.

Since settlement class was also determined to be on the increase continually over the years, then the increase in land surface temperatures over the years could be attributed to the increased settlement which is an indicator of urbanization. Figure 4 shows the derived LST maps for years 1989, 2000, 2010 and 2016.

Validation was done by comparing the ground observed data from Kenya Meteorological Department with the Land surface temperature as derived from the satellite image analysis and plotting the curves such as in Figure 4. The overall trend was compared visually through the curves and was found to be in agreement, with the ground data, though an offset was detected which could be explained by the fact that the ground stations measured ambient temperature whereas the satellite values were surface temperatures. Curves showing the overall trends in the ground data and satellite derived data are as shown in Figure 5.

\subsection{Analysis of the Correlation between LST and Urban Settlement}

In determining the correlation between land surface temperature and settlement, it was noted, as shown in the curve below, that there was a positive correlation between the two variables indicating that an increase in urban settlement lead to a positive increase in land surface temperature showing a positive correlation/relationship between the two variables. This was an indication of correlation i.e. a change in urban settlement leads to a proportional increase in surface temperature. Figure 6 shows the correlation between LST and urban settlement.

In further analyzing the correlation, a scatterplot of ground measurements versus satellite measurements revealed that for the years 1989, 2000 and 2010, the regression coefficient was above 0.5 which indicated a strong correlation between the ground-satellite observations thus giving confidence in the subse- 


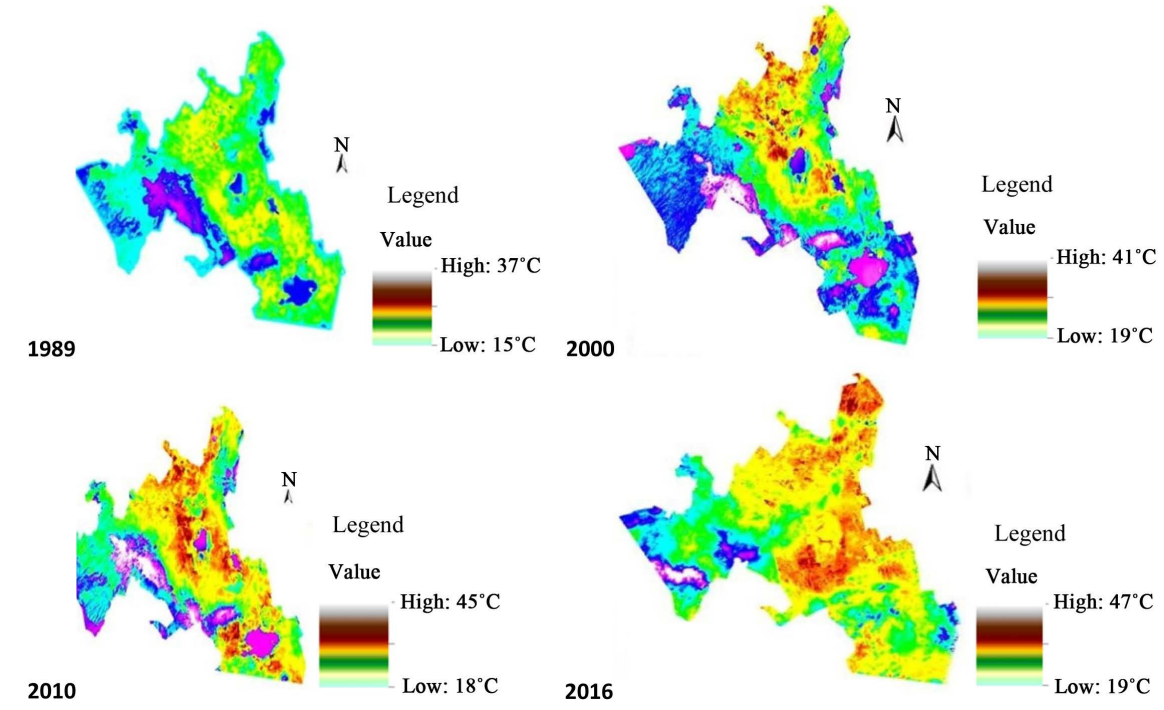

Figure 4. Derived land surface temperature map.

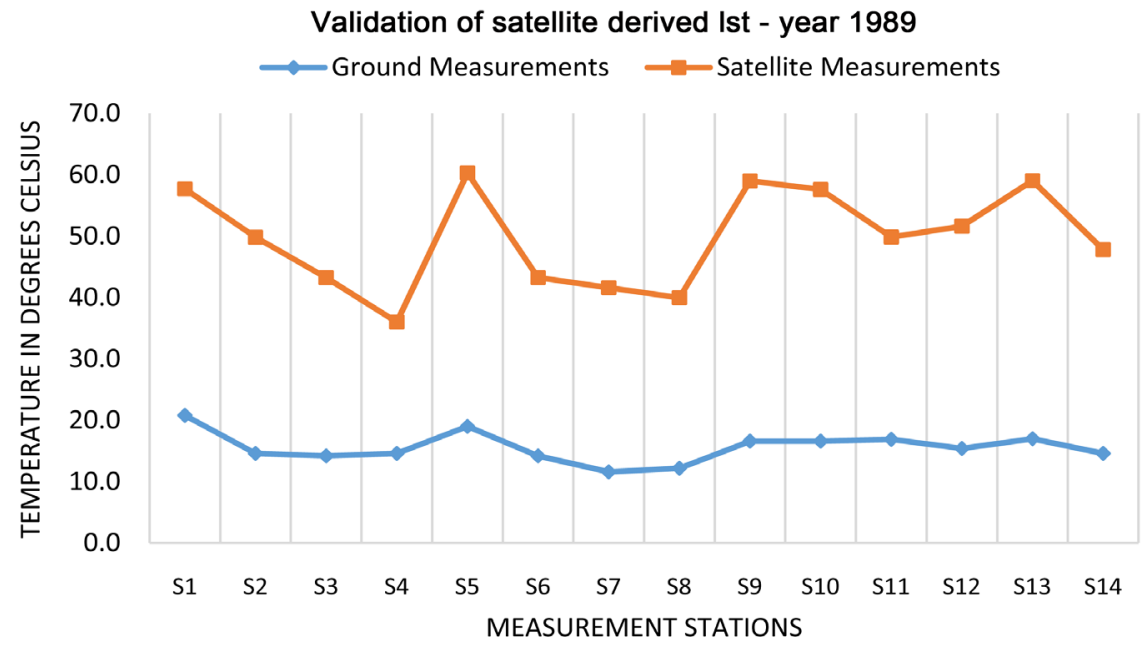

Figure 5. Satellite-ground validation.

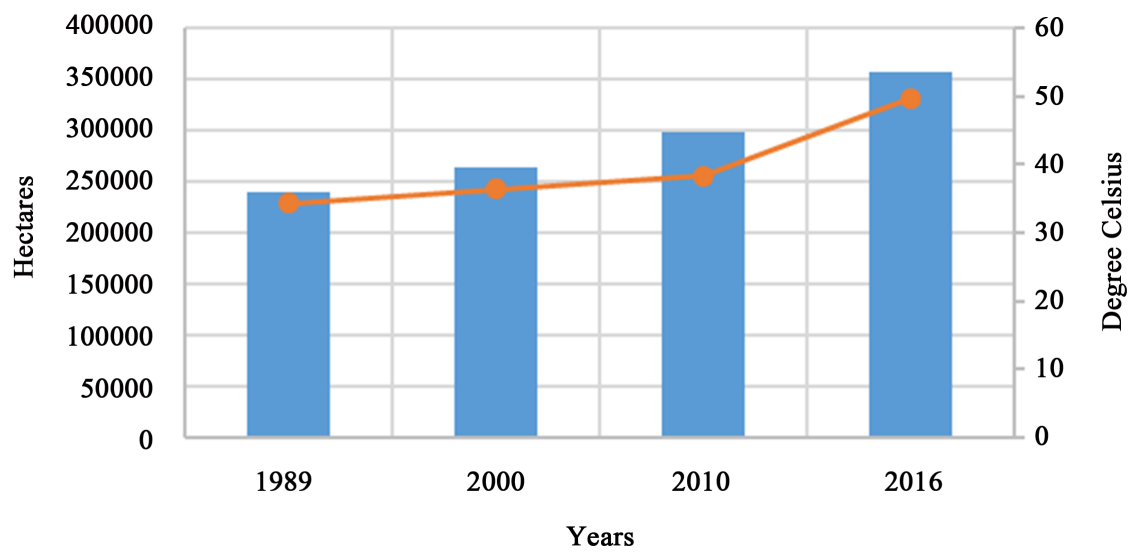

Urban (Hectares) $\quad \longrightarrow$ Temperature (Degree Celsius)

Figure 6. Correlation between LST and urban settlement. 
quent analysis that incorporate the land surface temperature. The results of the scatterplot, together with the regression coefficients are shown in Figure 7 and Figure 8.

\subsection{Simulating Land Surface Temperature for 2025}

Results of the least squares adjustment for the purpose of determining the coefficients of the interpolating polynomial to be used in forecasting the mean LST for the year 2025 are discussed in this section. Table 6 below shows the coefficients of the interpolating polynomial.

The R2 statistic was about 0.8 which was found to be quite satisfactory and

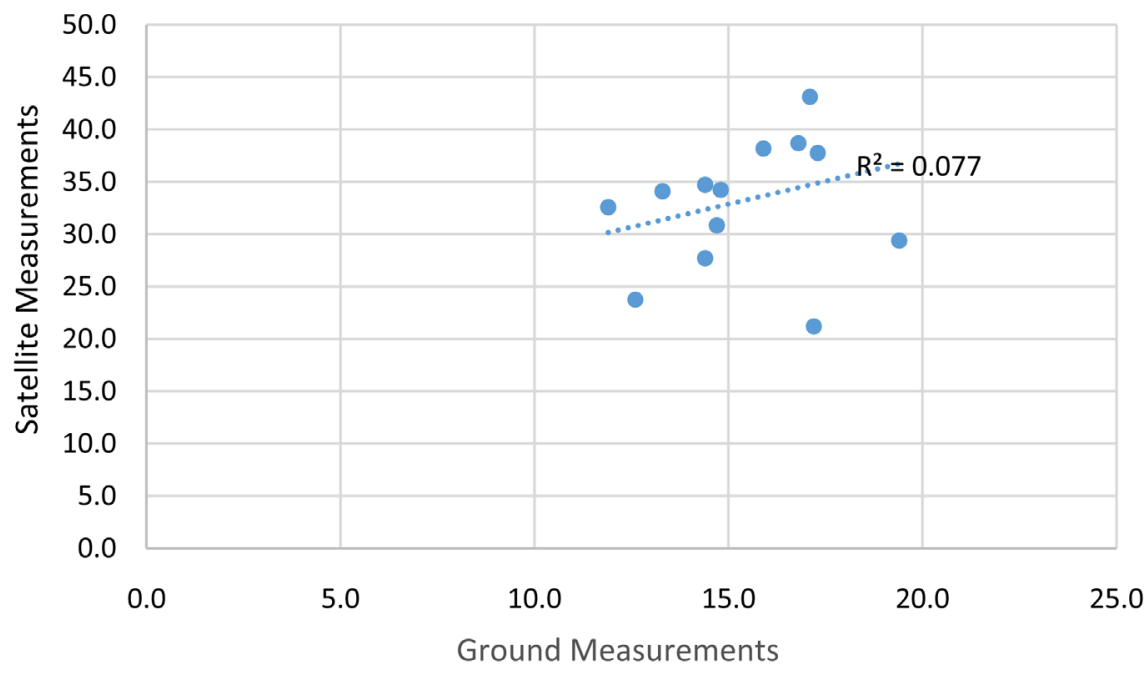

Figure 7. Ground-satellite validation scatterplot for 2000.

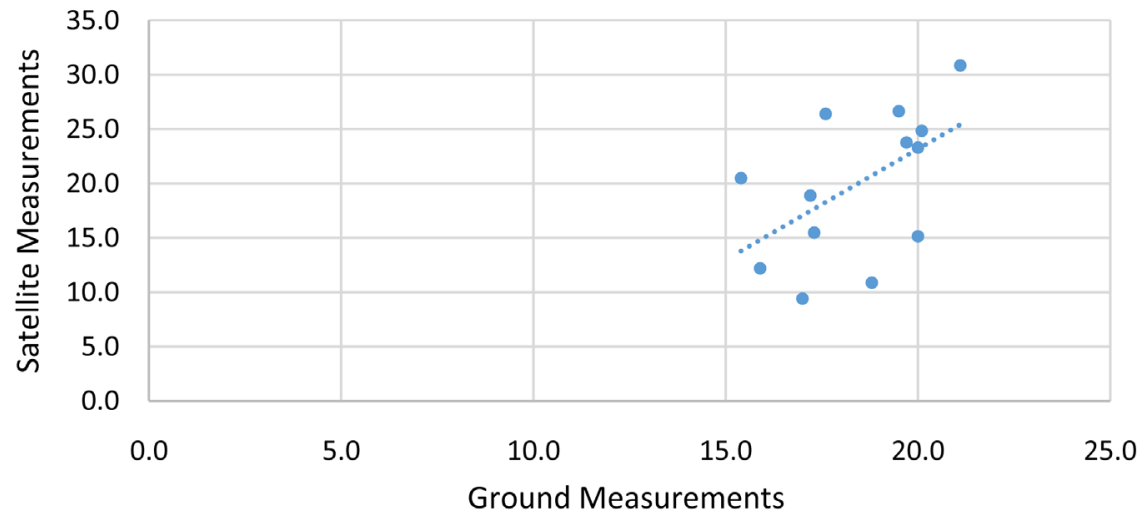

Figure 8. Ground-satellite validation scatterplot for 2010.

Table 6. Coefficients of the interpolating polynomial.

\begin{tabular}{ccccc}
\hline & Coefficients & Standard Error & $\mathrm{t}$ Stat & $P$-value \\
\hline Intercept & -1.8976556 & 75.64965681 & -0.02508 & 0.984034 \\
NDVI & -60.621072 & 144.911311 & -0.41833 & 0.747765 \\
NDBI & 0.3588581 & 61.54925142 & 0.00583 & 0.996288 \\
\hline
\end{tabular}


thus gave the confidence of using the model to predict the future LST. Therefore, the polynomial adopted, moving forward, was:

$$
\mathrm{LST}=-60.621 \mathrm{NDVI}+0.359 \mathrm{NDBI}-1.898
$$

The R2 statistic was about 0.8 which was found to be quite satisfactory and thus gave the confidence of using the model to predict the future LST. Therefore, the polynomial adopted, moving forward, was:

Historical data for NDVI and NDBI was plotted and the trends observed. Using this approach, the projected NDVI and NDBI values were estimated, with the underlying assumption that the trend shall proceed in a linear pattern. For each region of influence, NDBI and NDVI was estimated, for input to the interpolating polynomial, to derive LST for each region of influence. Figure 9 and Figure 10 show the prediction of NDVI and NDBI for the first region of influence.

In order to generate the LST surface, the Thiessen polygons were generated about the ground stations as obtained from the Kenya Meteorological Department. These Thiessen polygons acted as regions of influence, within which the

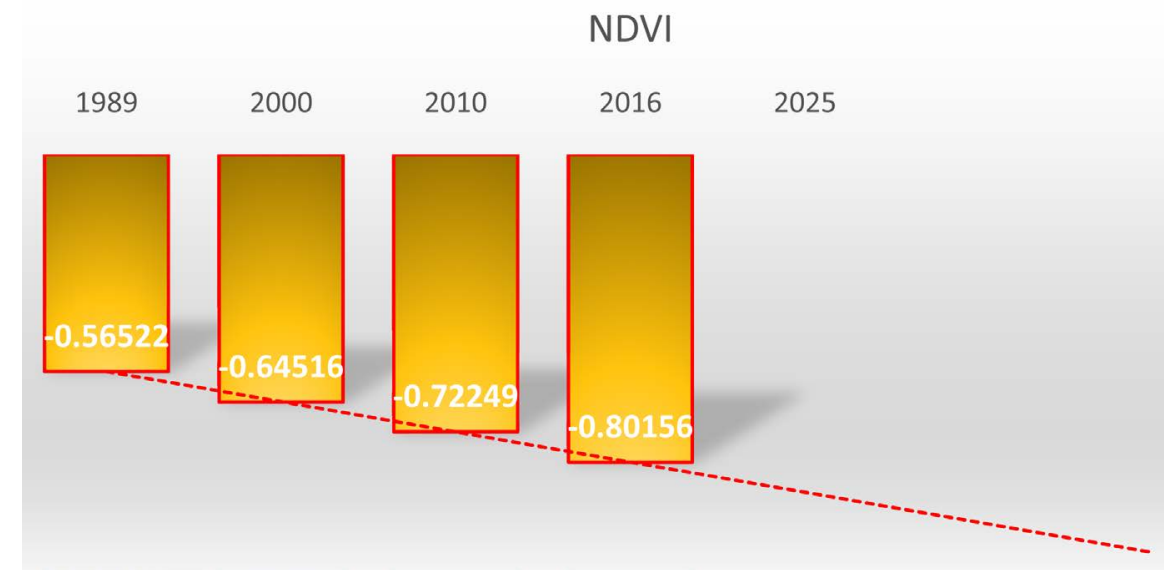

Figure 9. Prediction of NDVI for 2025 using linear trend line.

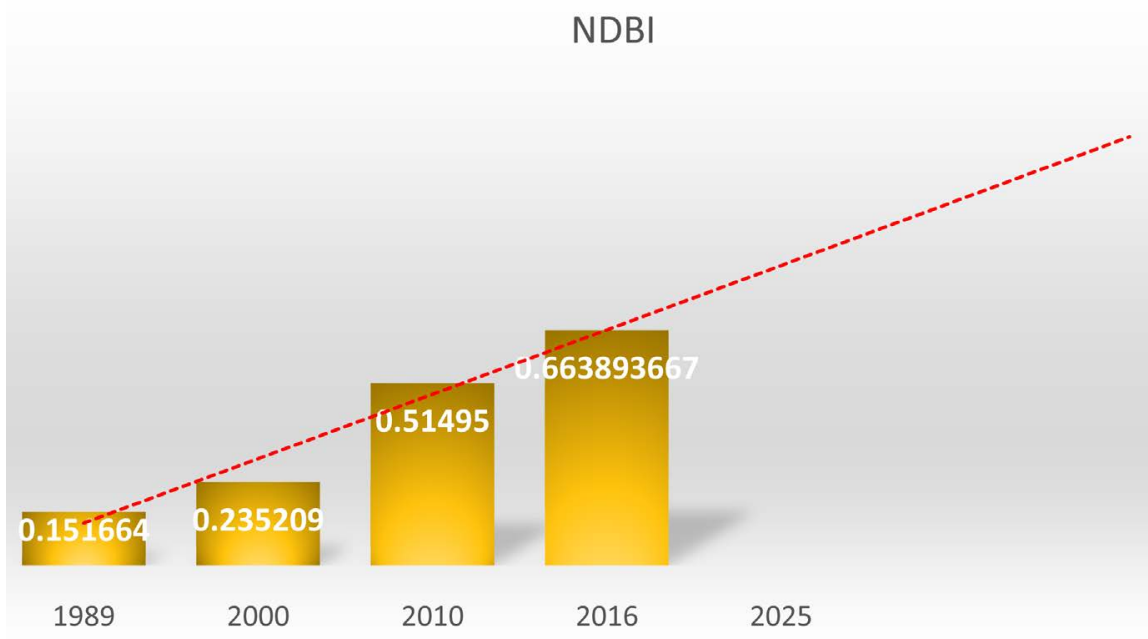

Figure 10. Prediction of NDBI for 2025 using linear trend line. 
temperature value would be assumed to be constant. Figure 11 shows the ground stations, together with the Thiessen polygons, that serve as the regions of influence. This implies that each polygon/region will have unique value of surface temperature.

To predict the LST, the predicted values of NDVI and NDBI were obtained by observing the trends over the years, for each region of influence as in Figure 11. The predicted NDVI and NDBI based on linear trend are shown in Table 7.

The predicted values of the independent variables (NDVI and NDBI) obtained from Table 7 were input into the interpolating polynomial LST $=60.621 \mathrm{NDVI}+$ $0.359 \mathrm{NDBI}-1.898$ to derive the projected LST for each region of influence. As a consequence, the projected LST for the year 2025 for the Nakuru County is documented in Table 8.

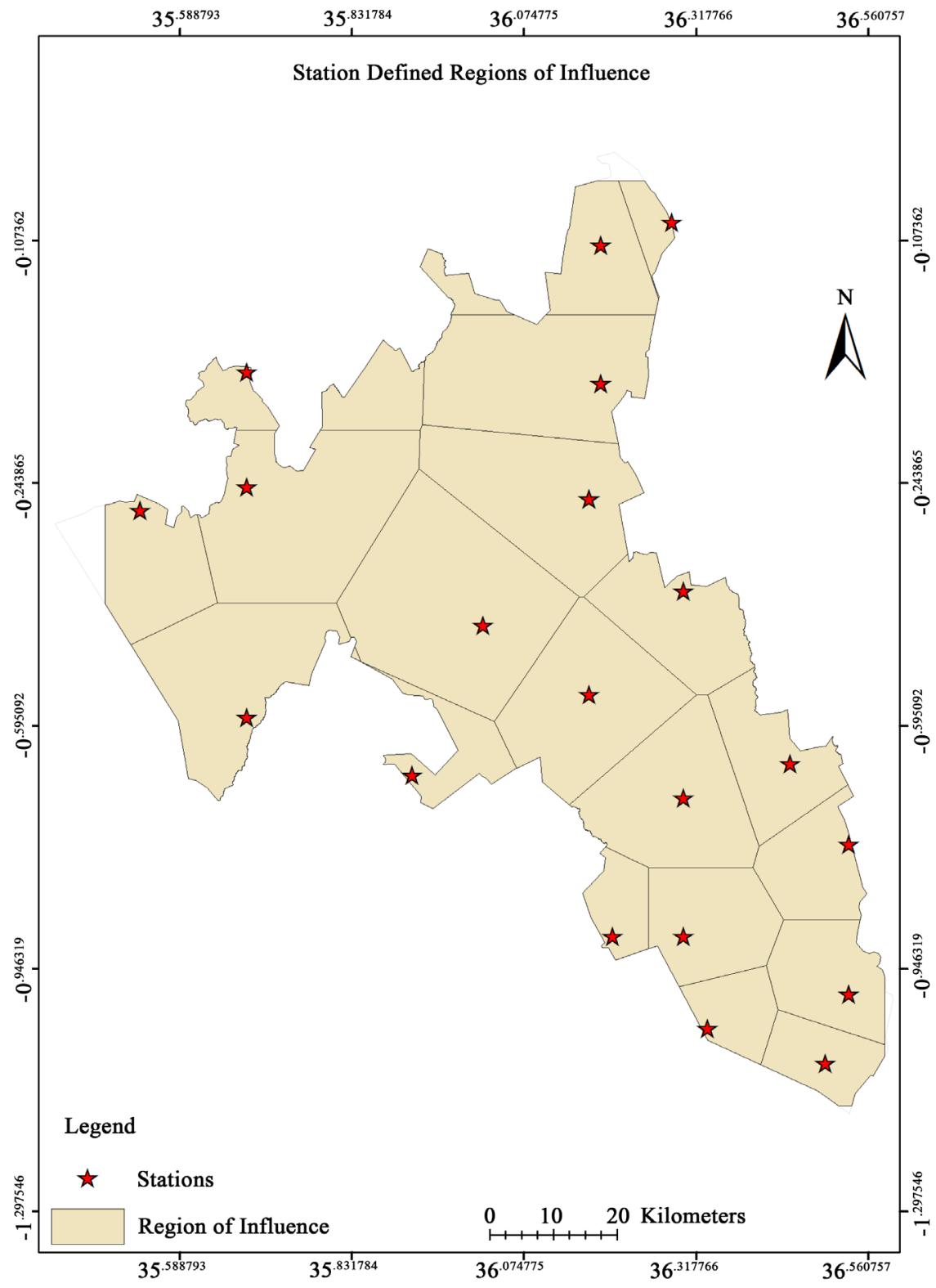

Figure 11. Station defined regions of influence generated through Thiessen polygons. 
Table 7. Predicted NDVI and NDBI for each region of influence.

\begin{tabular}{ccc}
\hline Region of Influence & Forecasted NDVI-2025 & Forecasted NDBI-2025 \\
\hline 1 & -0.20624 & 0.678482 \\
2 & -0.70347 & 0.882257 \\
3 & -0.62079 & 0.878212 \\
4 & -0.75156 & 0.679934 \\
5 & -0.56026 & 0.894259 \\
6 & -0.79688 & 0.871403 \\
7 & -0.89574 & 0.779612 \\
8 & -0.95223 & 0.855203 \\
9 & -0.60799 & 0.597869 \\
10 & -0.53277 & 0.746352 \\
11 & -0.75362 & 0.984778 \\
12 & -0.75826 & 0.61757 \\
13 & -0.79165 & 0.676003 \\
14 & -0.64538 & 0.778088 \\
15 & -0.69622 & 0.648228 \\
16 & -0.73128 & 0.615995 \\
17 & -0.63764 & 0.854937 \\
18 & -0.64257 & 0.496141 \\
\hline & &
\end{tabular}

Table 8. Forecasted LST for each region of influence.

\begin{tabular}{|c|c|}
\hline Region of Influence & Forecasted LST-2025 \\
\hline 1 & 10.8482 \\
\hline 2 & 41.06387 \\
\hline 3 & 36.05025 \\
\hline 4 & 43.9062 \\
\hline 5 & 32.38666 \\
\hline 6 & 46.72221 \\
\hline 7 & 52.68276 \\
\hline 8 & 56.13409 \\
\hline 9 & 35.17379 \\
\hline 10 & 30.66707 \\
\hline 11 & 44.14073 \\
\hline 12 & 44.29013 \\
\hline 13 & 46.3354 \\
\hline 14 & 37.50473 \\
\hline 15 & 40.54006 \\
\hline 16 & 42.65425 \\
\hline 17 & 37.06352 \\
\hline 18 & 37.23339 \\
\hline
\end{tabular}


The predicted values of LST were in the range 10.84 to 56.13. For purposes of visualization, these values were classified into 6 classes which were consequently used to generate a choropleth map, symbolized using the predicted LST for each region of influence. Each region of influence is represented by a uniform value. Figure 11 shows the LST as it varies from one region of influence to another.

The results indicate that most regions of Nakuru County which are near lakes and towns, though not all, shall experience mean temperatures greater than 41 degree Celsius. This is high land surface temperatures, when compared, relatively to those obtained in the year 1989. Based on this observation, we concluded that the increase in urbanization lead to a corresponding increase in land surface temperatures because the land surface temperatures correlated strongly with increase in settlement (urbanization). Therefore, future planning efforts need to incorporate the predicted rise in Urban Heat Island as one of the variables in their urban planning initiatives. Figure 12 shows the predicted land surface temperature for Nakuru for the year 2025.

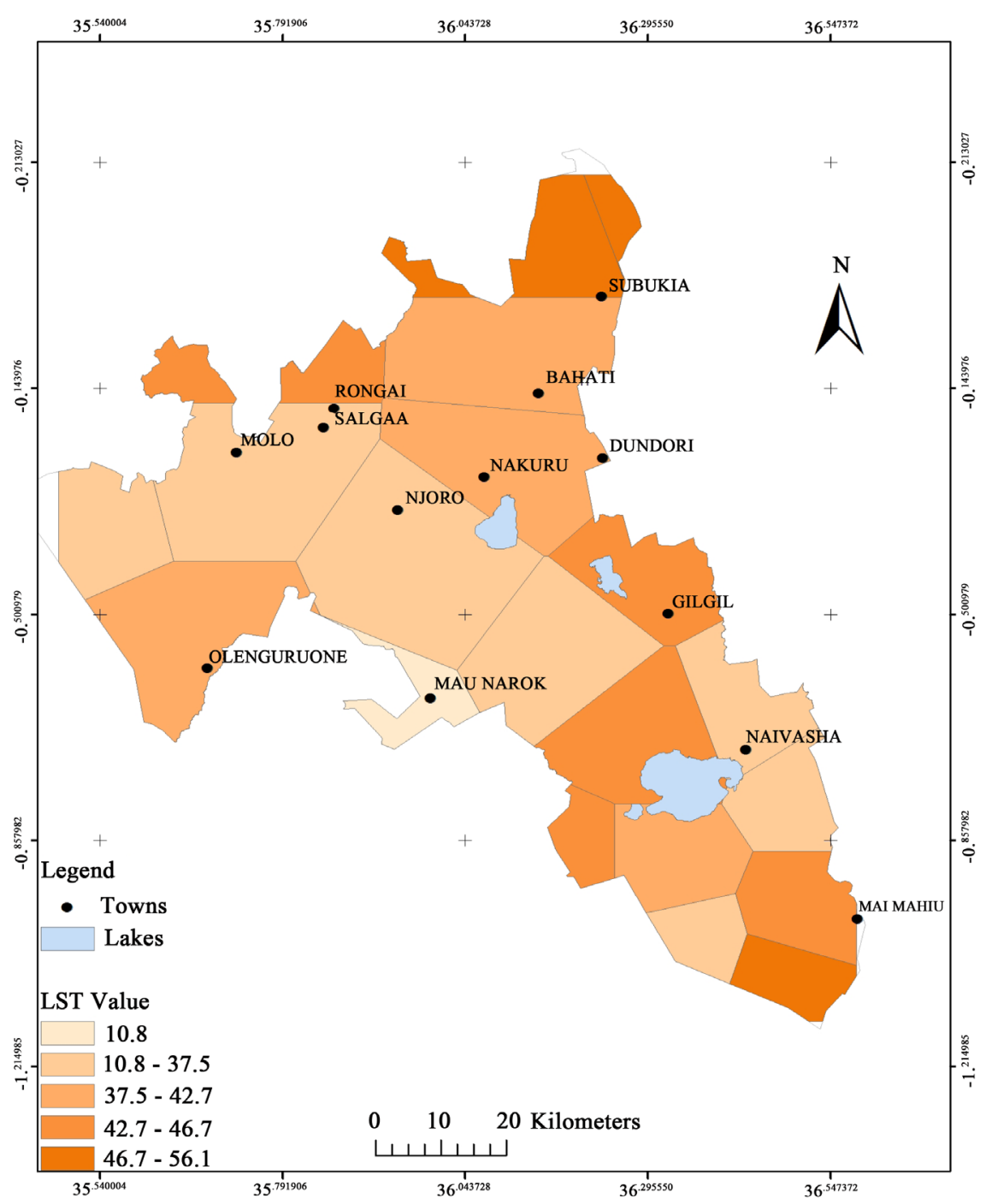

Figure 12. Predicted land surface temperature for 2025. 


\section{Conclusions}

The results demonstrate that settlement areas have increased over the years, which is a clear indication of increasing urbanization. On the other hand, cropland, grassland and forestland have significantly reduced over the time. In analyzing the change detection matrix, it was concluded that most of land use/land cover changed to settlement within the epoch in consideration and this also is an indicator increase in impervious surface which leads to rise in Urban Heat Island. With the Settlement gaining much proportion from other classes, vegetation cover reveals a continuous reduction of coverage to other classes. Reduction in vegetation cover is a factor leading to rise in Land Surface Temperature.

Analysis of the historical trends in the four instances in the time series on LST reveals that the mean temperature, as computed for each year, was increasing over the years in a manner likely to contribute to Urban Heat Island effect. The trend in LST reveals a close relationship with the significant increase in settlement and the corresponding reduction in vegetation cover.

In the determination of the correlation between Land Surface Temperature and Settlement, it was concluded that there was a strong and positive correlation between the two variables signifying that an increase in urban settlement leading to a corresponding positive increase in land surface temperatures. The results of the least squares adjustment for the purpose of determining the coefficients of the interpolating polynomial to be used in forecasting the mean LST for the year 2025 showed a strong R2 statistic of 0.8188 which is an indication of strong correlation in the variables used in the linear regression, therefore giving confidence in the results.

Furthermore, modeling future mean LST using regression equations revealed a consistent trend in the rise of LST showing that the Urban Heat Island phenomena was also on the increase. Since UHI is associated with impervious surfaces, it can be concluded that the trend translates to increase in Settlement/Urbanization and subsequent disappearance of vegetation cover.

\section{References}

[1] Gluch, R.Q.D. (n.d.) A Muilti-Scale Approach to Urban Thermal Analysis. Remote Sensing of Environment, 104, 123-132.

[2] Oke, T.R. (1982) The Energetic Basis of Theurban Heat Island. Quarterly Journal of the Royal Meteorological Society, 108, 1-24.

[3] Voogt, J.A. (2002) Urban Heat Island. In: Munn, T., Ed., Encyclopedia of Global Environmental Change, Wiley, Chichester, Vol. 3, 660-666.

[4] Coutts, et al. (2007) Impact of Increasing Urban Density on Local Climate: Spatial and Temporal Variations in the Surface Energy Balance in Melbourne, Australia. Journal of Applied Meteorology and Climatology, 46, 477-493. https://doi.org/10.1175/JAM2462.1

[5] Xie, Q.J. and Zhou, Z.X. (2013) Impact of Urbanization on Urban Heat Island and Effect Based on TM Imagery in Wuhan China. Environmental Engineering and Management Journal, 14, 647-655.

[6] Voogt, J.A. and Oke, T.R. (2003) Thermal Remote Sensing of Urban Areas. Remote 
Sensing of Environment, 86, 370-384.

https://doi.org/10.1016/S0034-4257(03)00079-8

[7] Yoshiki, Y. (2006) Measures to Mitigate Urban Heat Islands. Inter-Ministry Coordination Committee, Tokyo.

[8] Mumina. (2014) Dynamism of Land use Changes on Surface Temperatures in Kenya. International Journal of Science and Research, 1, 38-41.

Submit or recommend next manuscript to SCIRP and we will provide best service for you:

Accepting pre-submission inquiries through Email, Facebook, LinkedIn, Twitter, etc. A wide selection of journals (inclusive of 9 subjects, more than 200 journals)

Providing 24-hour high-quality service

User-friendly online submission system

Fair and swift peer-review system

Efficient typesetting and proofreading procedure

Display of the result of downloads and visits, as well as the number of cited articles Maximum dissemination of your research work

Submit your manuscript at: http://papersubmission.scirp.org/

Or contact jgis@scirp.org 